\section{Plasticidade cerebral: conceito(s), contribuições ao avanço científico e estudos brasileiros na área de Letras*}

Brain plasticity: concept(s), contributions to scientific advancement and Brazilian studies in the area of Language

Alan Ricardo COSTA (UNISC) alan.dan.ricardo@gmail.com

Peterson Luiz Oliveira da SILVA (UNINTER) professorpetersonlamper@gmail.com Rafael Tatsch JACÓBSEN (UNISC) rafaeltjacobsen@gmail.com

Recebido em: 01 de jan. de 2019. Aceito em: 25 de jun. de 2019.

*Pesquisa apresentada no $6^{\circ}$ Encontro da Rede Sul Letras, realizado na Universidade de Santa Cruz do Sul (UNISC), em 2018.
COSTA, Alan Ricardo; SILVA, Peterson Luiz Oliveira da; JACÓBSEN, Rafael

Tatsch. Plasticidade cerebral: conceito(s), contribuições ao avanço científico e estudos brasileiros na área de Letras. Entrepalavras, Fortaleza, v. 9, n. 3, p. 457-476, set-dez/2019.

Resumo: O objetivo maior do presente artigo é debater as contribuições do conceito de "plasticidade cerebral" no avanço científico brasileiro, sobretudo no que tange ao ensino e à aprendizagem de línguas. Para tanto, os objetivos específicos do trabalho são os seguintes: (a) debater o conceito de plasticidade cerebral, em relação aos conceitos de plasticidade neural, plasticidade neuronal e plasticidade sináptica, com base na literatura da área; (b) apontar contribuições dos estudos referentes à plasticidade cerebral em diferentes áreas do saber, como a Educação, a Psicologia e as Neurociências, mas com pontual ênfase na área da Linguística Aplicada; e (c) apresentar dados do estado da arte de pesquisas oriundas de Programas de Pós-Graduação - coletados a partir de buscas no Banco de Teses e Dissertações da CAPES - que abarcam discussões referentes à plasticidade cerebral no contexto nacional, com ênfase dada às publicações produzidas em Programas de Pós-Graduação (Mestrado e Doutorado) em Letras/Linguística e suas contribuições ao processo de ensino e aprendizagem de línguas.

Palavras-chave: Plasticidade Cerebral. Neurociências. Linguística Aplicada. 
v. 9 (3) 457-476 set-dez 2019

Abstract: The main objective of this article is to discuss the contributions of the concept of "brain plasticity" in the Brazilian scientific advance, especially with regard to language teaching and learning. In order to do so, the specific objectives of the study are: (a) to discuss the concept of brain plasticity, in relation to the concepts of neural plasticity, neuronal plasticity and synaptic plasticity, based on the literature of the area; (b) to point out contributions of studies related to brain plasticity in different areas of knowledge, such as Education, Psychology and Neurosciences, but with a specific emphasis on the area of Applied Linguistics; and (c) present state-of-the-art research data from postgraduate programs - collected from research on CAPES Theses and Dissertations Bank - which include discussions on brain plasticity in the national context, with emphasis on publications produced in Postgraduate Programs (Master's and Doctoral Degree) in Letters/Linguistics and their contributions to the process of teaching and learning languages.

Keywords: Brain Plasticity. Neurosciences. Applied Linguistic.

\section{Considerações iniciais}

Pensar o passado para compreender o presente e idealizar o futuro. - Heródoto.

A chamada "Década do Cérebro", isto é, a década de 1990, marcada por significativos avanços científicos e tecnológicos referentes às neurociências em nível global, converteu-se na "Era do Cérebro", ou Era of the Brain (EARL, 2014; OLIVEIRA, 2015). O interesse em estudos sobre o cérebro humano não apenas resistiu ao findar do século XX como também ganhou fôlego e novos rumos no século XXI em inúmeros países, como EUA (principalmente por meio da Iniciativa BRAIN¹'), Israel, Austrália, Nova Zelândia e Japão (LAVAREDA; DUARTE, 2016).

Também se inclui nessa empreitada o Brasil, representado principalmente por Miguel Nicolelis, um dos maiores neurocientistas em nível mundial, e por Roberto Lent e Suzana Herculano-Houzel, docentes da Universidade Federal do Rio de Janeiro (UFRJ), dentre outros estudiosos na área. Além disso, Ventura (2010), em publicação recente sobre a área da Neurociência no Brasil, elenca aspectos de importância latente para a consolidação de nosso país no estudo do cérebro humano, a saber: (1) a fundação e o crescimento da Sociedade Brasileira de Neurociências e Comportamento $(\mathrm{SBNeC})^{2}$; (2) o pioneirismo, nas décadas de 40 e 50 do século passado, das universidades públicas na pesquisa de temas afins (como a depressão), sobretudo a Universidade

\footnotetext{
${ }^{1}$ Brain Research Through Advancing Innovative Neurotecnologies.

${ }^{2}$ Originalmente Sociedade Brasileira de Psicobiologia, fundada por Elisaldo Carlini (VENTURA, 2010).
} 
Federal do Rio de Janeiro (UFRJ), a Universidade Federal de Minas Gerais (UFMG) e a Faculdade de Medicina da Universidade de São Paulo em Ribeirão Preto (USP-RP); e (3) a proposição e consolidação do Congresso de Neurociências Latinoamericano, Caribenho e Ibérico, cuja primeira edição deu-se em território nacional (Búzios). Em suma, o contexto nacional permite a interpretação de que seguimos a tendência global de avanço nas neurociências e nas investigações sobre o cérebro, e projetamos avançar ainda mais futuramente.

Para pensar o futuro, contudo, precisamos analisar o presente e o passado. Observações em retrospectiva nos permitem avaliar de forma mais crítica os avanços científicos, em movimentos contínuos de instauração de um paradigma científico e, na sequência, de revolução científica. Thomas Kuhn, em A Estrutura das Revoluções Científicas (1997), uma das mais ilustres obras das Ciências Humanas, define "paradigma científico" como um conjunto consolidado de atividades acadêmicas estruturadas e dirigidas a um caminho comum por um grupo significativo de pesquisadores. A "revolução científica", por conseguinte, é a superação do paradigma científico anterior (KUHN, 1997), a partir de novas proposições e epistemologias. Findar paradigmas prévios e instaurar novos, sobretudo por meio de perspectivas e conceitos emergentes, são movimentos necessários à academia contemporânea, para irmos além dos caminhos já trilhados e identificarmos caminhos que ainda queremos (ou devemos) trilhar.

Dentro do paradigma atual das pesquisas em neurociências, defendemos que o conceito de plasticidade cerebral merece destaque, por significar, em grande medida, uma revolução científica, em função da superação das noções retrógradas de cérebro "fragmentado" (em que cada parte, isoladamente, seria responsável por uma função) e "estático" (fixo, imutável). Nesse viés, a popularização do conceito de plasticidade cerebral, a partir do avanço da ciência moderna, permitenos (re)pensar aspectos inerentes à capacidade cognitiva do ser humano e ao seu processo de desenvolvimento e aprendizagem em inúmeros campos do saber, conforme discutiremos nas laudas a seguir.

Tendo em vista as considerações prévias, o objetivo geral do presente trabalho é debater as contribuições do conceito de "plasticidade cerebral" no avanço científico brasileiro, considerando o passado, o presente e o (possível) futuro do referido tema, sobretudo no que concerne aos estudos da área de Letras e aprendizagem de línguas. Nesse viés, cada seção deste artigo busca contemplar os objetivos específicos 
v. 9 (3)

457-476 set-dez 2019

a seguir: (1) definir e distinguir os conceitos de "plasticidade cerebral", "plasticidade neuronal", "plasticidade neural" e "plasticidade sináptica", com base na literatura da área; (2) elencar algumas das principais contribuições do debate científico sobre plasticidade cerebral ao longo da história, com vistas a avanços acadêmicos em áreas como a Psicologia, a Educação, a Neurociência e a Linguística Aplicada, entre outras; (3) apresentar o estado da arte presente nas dissertações de mestrado e teses de doutorado produzidas em Programas de PósGraduação em Letras/Linguística e suas possíveis contribuições ao processo de ensino e aprendizagem de línguas.

\section{"Plasticidades": conceitos diferentes}

Cumpre elucidar, inicialmente, que os conceitos de "plasticidade cerebral", "plasticidade neural", "plasticidade neuronal" e "plasticidade sináptica" podem ser compreendidos de forma sinonímica, sem grandes prejuízos de entendimento aos estudiosos ou leitores de algum texto da área. Grosso modo, todos os conceitos orbitam em torno da noção de capacidade adaptativa do cérebro em diferentes espectros: biológico, físico, cognitivo, mental, entre outros. A delimitação mais precisa de cada conceito, contudo, pode significar um mais profundo entendimento da discussão científica, haja vista que cada acepção realça pontualmente um objeto de estudo a ser considerado: o cérebro, ou o Sistema Nervoso Central (SNC), o sistema nervoso, os neurônios ou as sinapses.

A opção por distinguir os quatro conceitos pode ser facilitada pela leitura do artigo intitulado Plasticidade e regeneração funcional do sistema nervoso: contribuição ao estudo de revisão, de autoria de Oda, Sant'Ana e Carvalho (2002). No referido trabalho, os autores buscaram, na literatura científica, dados referentes à plasticidade no SNC e às caracterizações atribuídas à plasticidade neural, neuronal, cerebral e sináptica. Com isso, os autores apresentam um breve contexto histórico da evolução do conhecimento científico da área, que muito interessa ao presente artigo.

Com base no estudo mencionado, podemos ilustrar, primeiramente, o conceito de "plasticidade", o qual, em sentido amplo, é reflexo da capacidade de adaptação. Oda, Sant'Ana e Carvalho (2002, p.175) atestam que a plasticidade, enquanto capacidade que se encontra em todos os organismos vivos, é o que possibilita mudanças de características 
morfofuncionais de acordo com as exigências do ambiente. Nos seres humanos, entretanto, a reflexão sobre a plasticidade pode ser vista sob uma ótica mais complexa: ainda que com cérebros similares (do ponto de vista anatômico, fisiológico e bioquímico), humanos podem apresentar comportamento que difere de uma pessoa para outra, e tal diferença no comportamento reflete a plasticidade do cérebro para se adaptar ao meio (ODA; SANT'ANA; CARVALHO, 2002, citando GUTIÉRREZ, 1998; BERGMAN et al., 1998; e COLINO; MUÑOZ; VARA, 2002).

Nesse viés, essa "plasticidade" geral, enquanto capacidade adaptativa que contempla contingências filogenéticas e ontogenéticas, pode estar atrelada especificamente ao cérebro, ao sistema nervoso, aos neurônios ou às sinapses, o que nos permite a interpretação/ sistematização descrita a seguir:

a) Plasticidade cerebral: referente ao cérebro e sua capacidade de modificação ao longo da vida. No que tange a esse aspecto, cumpre elucidar que, há alguns anos, aceitavase que o tecido cerebral não contava com capacidade regenerativa. Por conseguinte, não se podia aclarar como, apesar disso, pacientes com lesões severas invalidantes, por exemplo, conseguiam determinadas recuperações. A esse respeito, explica-se:
A recuperação cerebral pode ocorrer gradativamente, entretanto os ganhos funcionais podem continuar por anos após a lesão. O grau de recuperação depende de diversos fatores, entre eles incluem: idade, área comprometida do cérebro, quantidade de tecido nervoso afetado, mecanismos de reorganização cerebral, assim como fatores ambientais e psicossocial (AGUILAR- REBOLLEDO, 1998, p. 514).

Ainda, a plasticidade cerebral pode, em lugar de ser entendida com ênfase no cérebro, ser definida como a capacidade adaptativa do SNC, "permitindo modificações na sua própria organização estrutural e funcional" (ODA; SANT'ANA; CARVALHO, 2002, p. 173). A opção pelo SNC, na qual o cérebro tem papel de destaque, aumenta a área de alcance do conceito. Nesse viés, os mecanismos através dos quais ocorrem a plasticidade cerebral incluem modificações neuroquímicas, sinápticas, do receptor, da membrana e ainda de outras estruturas neuronais (AGUILAR-REBOLLEDO, 1998).

${ }_{3}$ Obra citada: BERGMAN, R. A., et al. Histologia. México: McGraw-Hill. Interamericana. 1998. 
v. 9 (3) $457-476$ set-dez 2019

b) Plasticidade neural: A plasticidade neural pode ser definida genericamente:

como uma mudança adaptativa na estrutura e nas funções do sistema nervoso que ocorre em qualquer estágio da ontogenia, como função de interações com o ambiente interno ou externo ou, ainda, como resultado de injúrias, de traumatismos ou de lesões que afetam o ambiente neural (ODA; SANT'ANA; CARVALHO, 2002, p. 173, citando PHELPS, 19904, e VILLAR et al., 19985).

Por essa concepção, e em comparação com o conceito de plasticidade cerebral supracitado, podemos destacar que este último trata do $\mathrm{SNC}^{6}$, enquanto o primeiro conceito trata de todo o SN, composto tanto pelo SNC quanto pelo Sistema Nervoso Periférico (SNP).

Tendo em vista que o processo evolutivo "resultou em cérebros com uma abundância de circuitos neurais que podem ser modificados pela experiência" (ODA; SANT'ANA; CARVALHO, 2002, p. 171), e que tais circuitos neurais podem passar por modificações na estrutura neuroquímica de seus elementos, sobretudo no nível morfológico, podemos englobar tais modificações também dentro do conceito de "plasticidade neuronal".

Além disso, é fundamental considerar que tal plasticidade neural "está presente em todas as etapas da ontogenia, inclusive na fase adulta e durante o envelhecimento" (ODA; SANT'ANA; CARVALHO, 2002, p. 171). Essa premissa é recente: a capacidade de modificação do sistema nervoso em função de suas experiências, tanto em indivíduos jovens como em adultos e idosos, foi reconhecida apenas nas últimas décadas, com base em Rosenzweig (1996).

c) Plasticidade neuronal: referente aos neurônios. Como os neurônios não se dividem, sua destruição representa uma perda permanente, contudo, seus prolongamentos "dentro de certos limites podem se regenerar" (ODA; SANT'ANA; CARVALHO, 2002, p. 172; com base em GARTNER; HIATT, 1999; e JUNQUEIRA; CARNEIRO, 1999). A plasticidade neuronal é máxima durante o desenvolvimento, mas está

\footnotetext{
${ }^{4}$ Obra citada: PHELPS, C. H. Neural plasticity in aging and Alzheimer's disease: Some selected comments. Progress in Brain Research. 86: 3-10. 1990.

5 Obra citada: VILLAR, M. J.; CAVAZZOLI, C.; BRUMOVSKY, P. Capacidad adaptativa del sistema nervioso: mecanismos de plasticidade neural. Acta Psiquiat. Psico. At. 44(1): 11-27, 1998.
}

${ }^{6}$ Opinião compartilhada também por Silva e Kleinhans (2006). 
retida em parte no SNC adulto, manifestando-se como uma resposta a alterações de níveis hormonais, aprendizado de novas habilidades, resposta a alterações do meio e lesões (ROSENZWEIG, 1996).

Entre os tipos e modificações que caracterizam a plasticidade neuronal distinguem-se: (1) modificações que permitem manter as características dos elementos funcionais do sistema nervoso perante agressões, sejam físicas, químicas ou metabólicas; (2) variações observadas no curso da diferenciação e amadurecimento do sistema nervoso; e (3) mudanças no curso do processamento de informações e conduta adaptativa, que incluem distintos tipos de aprendizagem e armazenamento de informações. E morfologicamente evidenciase: (1) crescimento de novas terminações; (2) crescimento de botões sinápticos; (3) crescimento de espinhas dendríticas; (4) crescimento de áreas sinápticas funcionais; e (5) estreitamento da fenda sináptica (ODA; SANT'ANA; CARVALHO, 2002, p. 173, a partir das leituras de BRODAL, 1984; DOUGLAS, 1999; e COHEN, 2001).

d) Plasticidade sináptica: referente às sinapses (entre os neurotransmissores).

\begin{abstract}
Plasticidade sináptica pode ser definida como sendo as mudanças que ocorrem nas conexões interneuronais como plasticidade da expressão de moléculas neuroativas que levam a um aumento ou redução de síntese de diferentes neurotransmissores, desse modo o termo plasticidade é usado em tantas situações que ocorrem o risco de perda do seu significado original e o valor que tem para descrever alguns processos típicos e característicos do sistema nervoso (VILLAR et. al., $1998^{7}$ apud ODA; SANT'ANA; CARVALHO, 2002, p. 174).
\end{abstract}

A plasticidade sináptica a longo prazo é o conjunto de mudanças na eficácia sináptica que permanecem por mais de meia hora; a plasticidade sináptica a curto prazo, as que duram menos. Os mecanismos responsáveis pela expressão dessa plasticidade localizamse pré-sináptica e pós-sinapticamente (COLINO; MUÑOZ; VARA, 2002).

Oda, Sant'Ana e Carvalho (2002), com o respaldo das leituras de Brodal (1984) e Douglas (1999), entendem que a plasticidade sináptica engloba alterações moleculares como: alterações conformacionais em

7 Obra citada: VILLAR, M. J.; CAVAZZOLI, C.; BRUMOVSKY, P. Capacidad adaptativa del sistema nervioso: mecanismos de plasticidade neural. Acta Psiquiat. Psico. At. 44(1): 11-27, 1998. 
v. 9 (3) 457-476 set-dez 2019

moléculas de membrana, previamente existentes; alterações químicas de molécula de membrana, por fosforilação, acetilação ou metilação; alterações de conformação das proteínas receptoras; libertação ou descobrimento de receptores inativos e aumento dos sítios de ligação para moléculas transientes.

Em suma, portanto, a plasticidade cerebral pode ser entendida como esse conceito maior, amplo, que trata de modo generalista das funções adaptativas do cérebro. Por outro lado, as delimitações mais específicas do conceito apontam para divergências do objeto em questão: a "plasticidade cerebral" refere-se ao SNC, a "plasticidade neural" refere-se ao SN, a "plasticidade neuronal" refere-se aos neurônios e a "plasticidade sináptica" refere-se às sinapses, com base na literatura da área (ODA, SANT'ANA; CARVALHO, 2002).

\section{Uma noção que reverbera em diferentes áreas}

Nesta seção, apontamos algumas das principais contribuições dos estudos acadêmicos e da pesquisa científica embasada na concepção de "plasticidade cerebral". Haja vista o amplo número de campos do saber e perspectivas teóricas estudadas no meio acadêmico na atualidade, o debate recairá apenas sobre algumas áreas específicas, a começar pela Psicologia.

Historicamente, o conceito de "plasticidade cerebral" remete à obra de Vygotsky (1989). O cérebro humano, para Vygotsky, é caracterizado como: (a) órgão principal da atividade humana; (b) produto de longa evolução, e (c) sistema aberto, com alta plasticidade (REGO, 1995). Com esses três apontamentos sobre o cérebro, o pesquisador bielo-russo não apenas traz o conceito de plasticidade cerebral para o centro das discussões de uma área dita "Psicologia da Educação", mas também efetiva, no âmbito acadêmico, a superação da chamada "Crise da Psicologia" (REGO, 1995) nos anos de 1920, fundada no antagonismo extremo entre as perspectivas psicológicas anteriores: ambientalismo e inatismo.

Vygotsky entendia que ambas tendências [ramo com características de ciência natural, e ramo com características de ciência mental], além de não possibilitarem a fundamentação necessária para a construção de uma teoria consistente sobre os processos psicológicos tipicamente humanos, acabaram promovendo uma série crise na psicologia (REGO, 1995, p. 28). 
Por sua alta plasticidade, o cérebro humano não está à mercê única e exclusivamente de elementos e fenômenos externos ao sujeito (ambiente), tampouco resume-se a produto de aspectos biológicos (inatismo). Em contrapartida, relaciona-se a ambos. Por conseguinte, Vygotsky funda uma "Psicologia geral", na qual o cérebro, com sua plasticidade, tem o papel de superar uma cisão prejudicial aos métodos de fazer da Psicologia contemporânea.

Na área da Educação, as contribuições históricas e científicas do conceito de "plasticidade cerebral" são inúmeras, e elas podem ser mais bem concebidas a partir de duas conclusões de Oda, Sant'Ana e Carvalho (2002, p. 175), quais sejam: (1) "Todo aprendizado é uma forma de plasticidade", e (2) "A plasticidade continua por toda vida como um dos mecanismos de obtenção dos ajustes necessários para responder às exigências funcionais". Destarte, toda aprendizagem se dá por meio da plasticidade cerebral, que pode ser vista, ainda que mais subliminarmente, na obra de inúmeros educadores.

Um destes, de renome no cenário nacional e internacional, é o educador Paulo Freire. Para Freire (1996), o ser humano é um ser histórico, cultural, inacabado. Mais que inacabado, todos os sujeitos são, também, conscientes do inacabamento e em permanente movimento de busca do ser mais (com vocação ontológica ao "ser mais"). Nesse sentido, alguns axiomas da perspectiva freireana são: (a) sempre podemos aprender mais e (b) nunca paramos de aprender. Isso está diretamente relacionado ao cérebro, órgão máximo da aprendizagem humana, e sua plasticidade. Ainda que, na maioria de suas publicações, Freire não empregue os termos "cérebro" e "plasticidade", suas teorias educacionais estão ancoradas na capacidade de os sujeitos (principalmente nos papéis de "educador" e "educando") repensarem suas práticas, crenças, opiniões, posturas, visões de mundo e assim por diante.

Também é possível trazer ao debate o papel da plasticidade sináptica na memória humana. Para Izquierdo (2004b), resumidamente, memória é a aquisição, conservação e evocação de informações. A perda da memória, segundo o autor, pode ocorrer quando uma sinapse se atrofia pela falta de uso, ou desaparece por dano ou morte celular, caracterizando, assim, o esquecimento propriamente dito: as memórias desaparecem porque desaparecem as células que as (con)tinham (IZQUIERDO, 2004a). 
v. 9 (3) 457-476 set-dez 2019

Na literatura da área, os estudos enfocando a memória do idoso têm sido os mais populares. Pinto (1999), a esse respeito, comenta que a preocupação com a memória não pode ser um fenômeno de modismo, ou apenas das pessoas que estão se tornando idosas, menos ainda de preocupação apenas com as técnicas mnemônicas que existem desde a Antiguidade.

O que se torna importante em tais estudos, hoje, é saber que, graças atécnicas de "visualização" no cérebrodos correspondentesneurobiológicos, "é possível saber o que se passa no cérebro quando este recebe um estímulo cognitivo graças ao desenvolvimento da neurofisiologia" (PINTO, 1999, p. 45). Tais procedimentos podem ser valorizados pela compreensão do conceito de plasticidade cerebral, que, para Pinto (1999, p. 45) indica "a capacidade do cérebro de se modificar favoravelmente em sua estrutura e funcionamento, sob o efeito de estímulos apropriados e constantes". Nesse viés, a neurobiologia contemporânea possibilitou a fundamentação científica de "programas de ativação cerebral", com base nas noções de plasticidade cerebral (PINTO, 1999).

No que concerne à memória de idosos, o conceito de plasticidade cerebral é profícuo em romper com estereótipos ou com o senso-comum referente ao envelhecimento cognitivo, que supostamente perderia a capacidade de aprender. Sobre esse tópico, Dorneles, Cardoso e Carvalho (2012) são enfáticas ao defender que os mais velhos conservam boas capacidades para aprender, sobretudo quando a eles são dadas condições de motivação e atitudes adequadas, embora em um nível um pouco menor de execução das atividades quando em comparação com jovens. A capacidade cognitiva de aprendizagem no idoso mantém-se, ainda que com leve diminuição de seu potencial, porque:

O cérebro adulto é maleável e, devido à plasticidade, se adapta continuamente a novas circunstâncias. Essa capacidade cerebral de mudanças é atribuída à plasticidade cerebral, a qual sugere o cérebro estar bem constituído para a aprendizagem ao longo da vida e para adaptação ao ambiente. Nesse sentido, a forma como o processo de ensinar e aprender são conduzidos pode contribuir com os processos de ativação do cérebro devido à plasticidade, mas, para isso, são necessários estímulos (DORNELES; CARDOSO; CARVALHO, 2012, p. 252-253).

Segundo as autoras (DORNELES; CARDOSO; CARVALHO, 2012), é possível afirmar que o cérebro continua plástico e flexível na idade adulta, e isso reforça de forma positiva tanto o potencial da educação das pessoas idosas quanto a importância do retorno à escolarização e a continuidade dos estudos por parte dos mais velhos. 
De modo assemelhado, no campo da Linguística Aplicada, que historicamente se ocupa de questões de ensino e de aprendizagem de línguas e seus vários aspectos inerentes (métodos e abordagens de ensino, papel do professor, papel do aluno, materiais didáticos, conceitos inerentes à aquisição e aprendizagem, entre outros), vale citar a importância da plasticidade cerebral para o entendimento do conceito de "fossilização de erros". A fossilização de erros, nos estudos sobre aprendizagem de segunda língua ou de línguas estrangeiras, remete ao fenômeno linguístico de reaparecimento regular de estruturas linguísticas que não correspondem às da língua-alvo (ou Língua Objeto) produzidas por aprendizes que se fixam na interlíngua desses estudantes (DURÃO, 2000).

Não fosse a postulação de um paradigma que compreende o cérebro com sua plasticidade e dinamismo, estaríamos ainda hoje presos a uma noção de fossilização ad eternum, que eventualmente ainda aparece em alguns discursos pessimistas e reducionistas que alegam que determinado estudante ou pessoa "nunca vai aprender" tal coisa. Partimos do pressuposto de que nenhuma fossilização é eterna: toda fossilização é um devir, o fenômeno per se é em processo. Isso implica assumir que a fossilização é um período de transição de uma língua a outra e, como toda transição, embora possa ser mais breve para alguns e mais longa para outros, tem determinada duração de tempo. Isso está indiretamente relacionado ao conceito de plasticidade cerebral, tendo em vista que, se o cérebro humano não fosse dotado de alta plasticidade e capacidade adaptativa, realmente a fossilização de erros de estruturas linguísticas seria uma fossilização de fato.

Destarte, alegar que um determinado estudante não aprenderá assunto $\mathrm{X}$ ou estrutura linguística $\mathrm{Y}$, mesmo que se passem cem anos, por assim dizer, cabe como hipérbole, ou como uma anedota, apenas. Mas jamais pode ser uma alegação válida enquanto perspectiva pedagógica séria, comprometida e em sinergia com as discussões científicas contemporâneas, haja vista que, enquanto houver atividade cerebral, haverá possibilidades de aprendizagem.

Afora isso, cumpre elucidar: a acepção de "revolução científica" (KUHN, 1999) aludida neste artigo está atrelada, sobretudo, à noção de plasticidade cerebral como "remédio anti-determinista". Em outras palavras, de modo algum queremos desconsiderar o que as neurociências postularam de forma concreta enquanto teoria e pesquisa empírica, como, por exemplo, a noção de "período crítico" (FERRARI 
v. 9 (3) 457-476 set-dez 2019

et al., 2001). Queremos, por outro lado, complexificar tais noções e contribuir para uma revisão de visões ainda oriundas de uma tradição científica que, a priori, entendia o cérebro como estanque, fechado, "concluído" e sem capacidade adaptativa. O período crítico, nesse viés, ainda que sinalize períodos de maior plasticidade neural ou de maior capacidade de reorganização e de recuperação funcional em cérebros jovens, em comparação com adultos (FERRARI et al., 2001), não sinaliza uma incapacidade determinista por parte de algum indivíduo fora da "janela de tempo" do período crítico. No caso hipotético do ensino e da aprendizagem de italiano, ainda que um menino de 10 anos, em plena alfabetização e letramento, possa aprender talvez de forma mais rápida e dinâmica, uma senhora idosa, com seus 60 anos de idade, ainda que com mais dificuldade, também pode consegui-lo.

Finalmente, elencamos aqui apenas algumas ilustrações de avanços científicos das últimas décadas direta ou indiretamente relacionados ao conceito de "plasticidade cerebral". Outros exemplos, contudo, poderiam ser registrados, como os avanços nas áreas biológicas e médicas, haja vista que muitas patologias neurodegenerativas estão relacionadas à perda da neuroplasticidade (como o mal de Alzheimer, a doença de Huntington e a doença de Parkinson).

\section{Estado da arte de pesquisas brasileiras}

Nesta seção, apresentamos um breve estado da arte referente às dissertações de mestrado e às teses de doutorado oriundas de Programas de Pós-Graduação (PPG) e Programas de Pós-Graduação em Letras (PPGL) disponíveis no Banco de Teses e Dissertações da CAPES ${ }^{8}$. Em suma, foi realizado o mesmo procedimento metodológico adotado em Costa et al. (2016), a saber: escolha de palavras-chaves para nortearem as buscas por dissertações e teses disponibilizadas digitalmente no Banco de Teses e Dissertações da CAPES desde o ano 2000". As palavras-chaves escolhidas foram "Plasticidade cerebral", "Plasticidade neuronal", "Plasticidade neural" e "Plasticidade sináptica". As buscas foram realizadas nos meses de maio e junho de 2018.

Os resultados (isto é, as publicações mapeadas) foram catalogadas em tabelas com seus principais dados, como: autor, ano

\footnotetext{
${ }^{8}$ Disponível em: <http://catalogodeteses.capes.gov.br/catalogo-teses/\#!/> .

9 Portanto, a pesquisa considerou dissertações e teses defendidas entre os anos 2000 e 2017. Não podíamos garantir que publicações acadêmicas do ano de 2018 estavam atualizadas no Banco da CAPES.
} 
de publicação, instituição ao qual a pesquisa estava vinculada, título, resumo, palavras-chave etc.. A partir da análise comparativa dos dados (em um viés quantitativo), e com base na leitura dos resumos (em um viés qualitativo), foi possível sistematizar os resultados e as discussões a seguir.

A começar pela quantificação, descrição e avaliação dos trabalhos mapeados. A tabela 1 evidencia o número de publicações localizadas discriminadas por: (a) palavra-chave empregada na busca, (b) caracterização da publicação (se dissertação de mestrado ou tese de doutorado) e (c) área do saber (se especificamente de algum PPG de Letras/Linguística ou se de outros programas, como da Psicologia, da Educação, da Comunicação e outros).

Tabela 1 - Número de teses e dissertações disponíveis no Banco de Teses da CAPES, a partir da busca por palavras-chave.

\begin{tabular}{c|c|c|c|c}
\hline \multirow{2}{*}{$\begin{array}{c}\text { Palavra- } \\
\text { chave da } \\
\text { busca }\end{array}$} & \multicolumn{2}{|c|}{ Campos do saber em geral } & \multicolumn{2}{c}{ Letras/Linguística } \\
\cline { 2 - 5 } & Teses & Dissertações & Teses & Dissertações \\
\hline $\begin{array}{c}\text { "Plasticidade } \\
\text { cerebral" }\end{array}$ & 22 & 56 & 1 & 7 \\
\hline $\begin{array}{c}\text { "Plasticidade } \\
\text { neuronal" }\end{array}$ & 61 & 98 & 0 & 0 \\
\hline $\begin{array}{c}\text { "Plasticidade } \\
\text { neural" }\end{array}$ & 70 & 89 & 0 & 0 \\
\hline $\begin{array}{c}\text { "Plasticidade } \\
\text { sináptica" }\end{array}$ & 89 & 113 & 0 & 0 \\
\hline \multicolumn{2}{c}{ Fonte: Os autores. }
\end{tabular}

Conforme pode ser vislumbrado na tabela, o termo "Plasticidade cerebral" foi aquele, nas demais áreas do saber, com o menor número de resultados ( 78 pesquisas, sendo 22 teses de doutorado e 56 dissertações de mestrado). Já em relação ao campo de Letras/Linguística, o resultado inverte-se: apenas trabalhos com o escopo em "plasticidade cerebral" foram mapeados. A razão para isso talvez se dê em função do termo "Plasticidade cerebral" ser, em grande medida, o mais amplo e geral. As expressões "plasticidade neuronal", "plasticidade neural" e "plasticidade sináptica", por apresentarem uma nomenclatura mais própria de áreas médicas e biológicas, por exemplo, passam a ser mais presentes em dissertações e teses oriundas de PPGs dessas áreas, enquanto que a expressão "plasticidade cerebral" é suficientemente ampla, mas ao mesmo tempo suficientemente eficaz, para dar conta das discussões inerentes à área de Letras/Linguística. 
V. 9 (3)

457-476 set-dez 2019

Ainda em comparação, contudo, não podemos deixar de salientar o contraste notório entre os demais campos do saber e a área de Letras/ Linguística. Aparentemente, poucos trabalhos da área de Letras/Linguística ocupam-se de questões envolvendo a plasticidade cerebral e seu papel na aquisição e na aprendizagem de línguas (seja língua materna, seja língua estrangeira ou, ainda, segunda língua). Podemos tentar considerar alguns motivos para explicar esse reduzido número de trabalhos. O primeiro deles talvez seja a tradição da disciplinaridade que ainda impera em muitas áreas do saber. Como forte herança do positivismo científico, ainda temos mais "fronteiras" do que "pontes" entre alguns campos do saber. Nesse viés, aparenta ser necessário um maior diálogo entre o campo de Linguística e áreas com interesses afins, como as neurociências.

O segundo aspecto a considerar é a recente ascensão das discussões neurolinguísticas na área de Letras. Dos 8 trabalhos oriundos do campo de Letras/Linguística, um deles data de 2003, outro, data de 2012. Os demais foram defendidos em 2015 (três trabalhos) e em 2016 (outros três trabalhos). Tais dados demonstram que a temática em questão é ainda incipiente nas discussões linguísticas dos programas de pós-graduação no Brasil, mas que há uma tendência de elevação da presença desse tema na área.

Esse segundo aspecto nos levou a considerar as datas de publicações, não só na área de Letras, mas em todos os campos do saber. Com base no Gráfico 1, mostramos o interesse crescente nas temáticas em questão a partir dos triênios de avaliação.

Gráfico 1 - Crescimento do número de dissertações e teses no séc. XXI, no Brasil, por triênios.

Publicações no que concerne aos anos da defesa da pesquisa

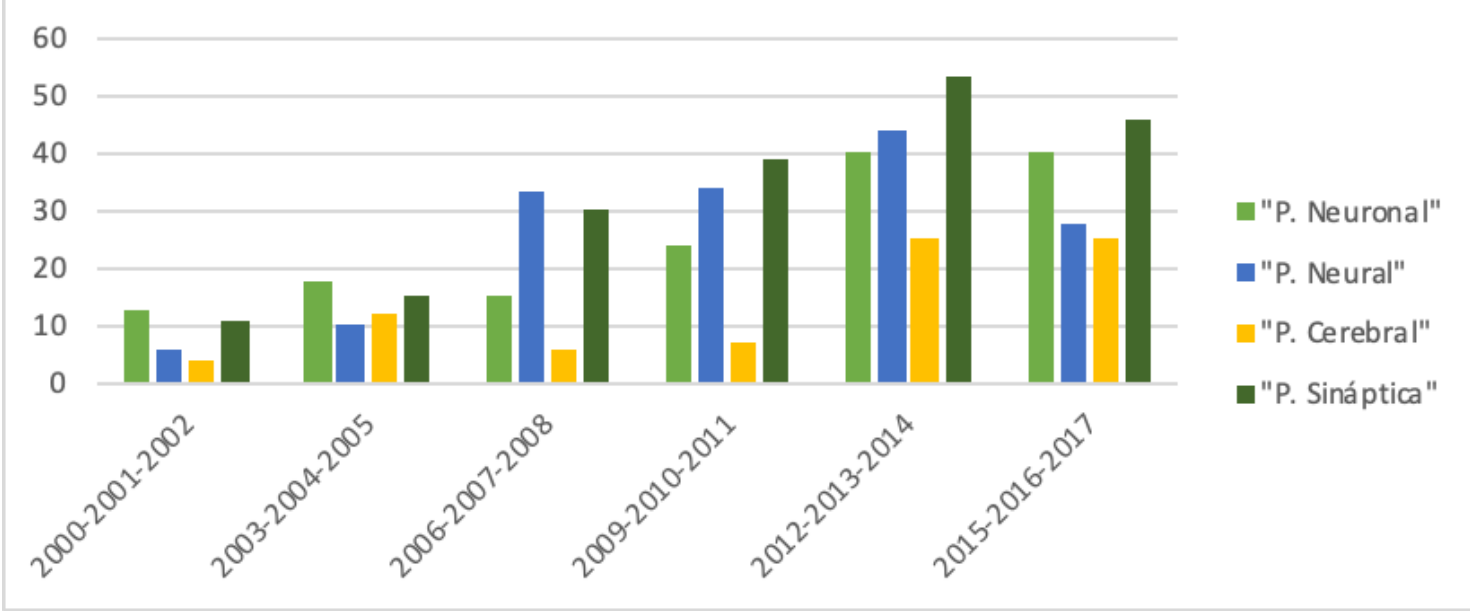

Fonte: Os autores. 
Ao longo dos triênios, o crescimento de pesquisas que abordam o tema deu-se tanto de modo geral, considerando quantitativamente as publicações sobre as quatro temáticas em separado ("plasticidade cerebral", "plasticidade sináptica", "plasticidade neural" e "plasticidade neuronal"), quanto de modo específico, considerando cada temática individualmente. Também com base nos dados evidenciados, o número de pesquisas abordando a plasticidade sináptica é maior do que os demais temas.

A identificação das IES com os PPG (não apenas os PPGL) que poderiam ser considerados referências nos estudos neurolinguísticos também se mostrou oportuna. A Universidade Estadual de Campinas (Unicamp), a Universidade de São Paulo (USP) e a Universidade Federal do Rio Grande do Sul (UFRGS), conforme mostra o Quadro 1, são as instituições que contam com o maior número de dissertações e teses defendidas envolvendo os estudos sobre a plasticidade cerebral.

Quadro 1 - Gráficos com as principais IES no que tange às produções de dissertações de mestrado e teses de doutorado envolvendo os estudos de "plasticidade cerebral", "plasticidade sináptica", "plasticidade neural" e "plasticidade neuronal".

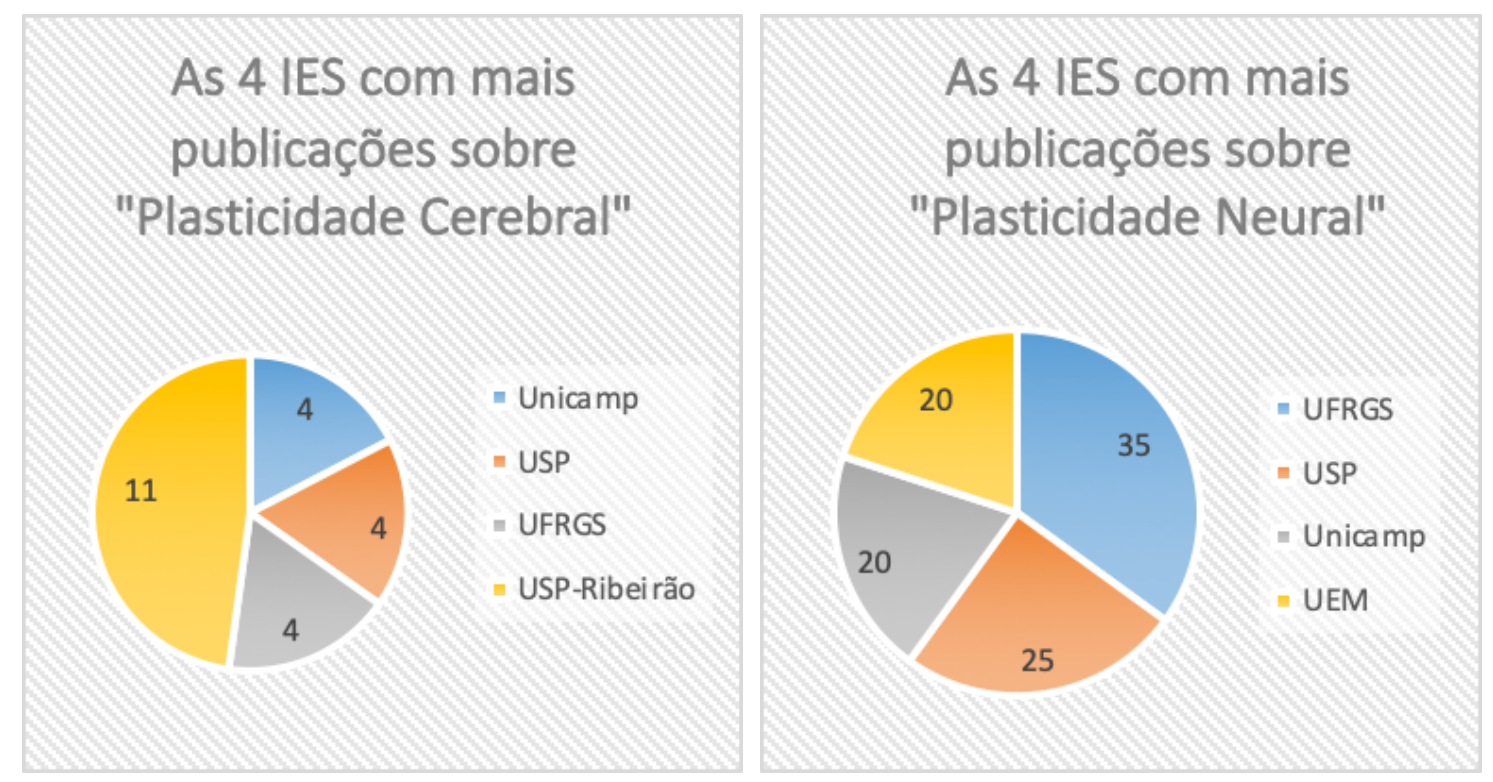


v. 9 (3)

457-476 set-dez 2019

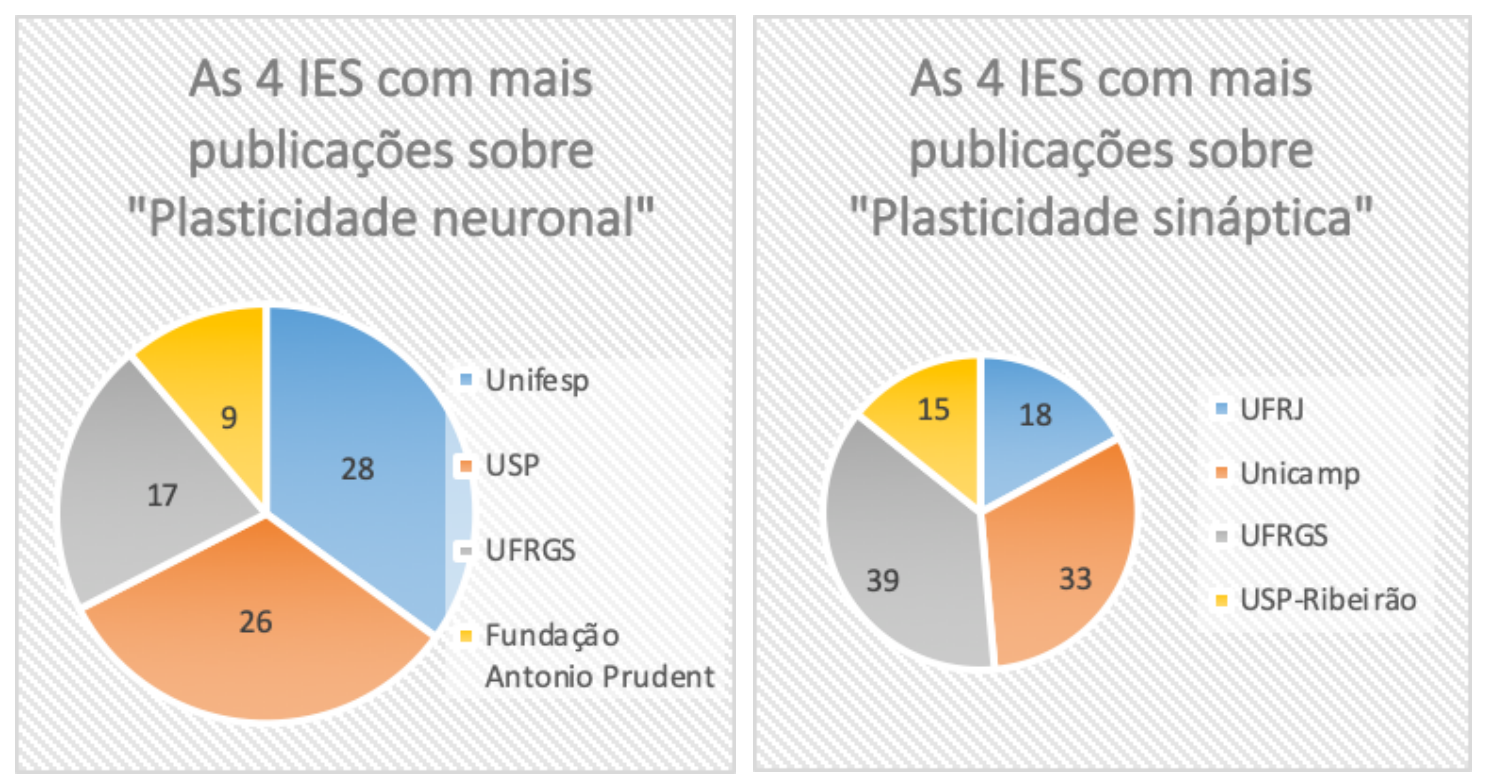

Fonte: dos autores.

Finalmente, a partir da leitura dos oito resumos de dissertações e teses na área de Letras/Linguística (ver Tabela 1), podemos sugerir leituras para pesquisadores, professores e estudiosos de línguas que queiram apropriar-se de forma mais aprofundada de publicações acadêmicas que abarquem as discussões sobre plasticidade cerebral. Pontualmente, recomendamos a leitura das dissertações de mestrado a seguir.

1) "A leitura dos nativos digitais: uma abordagem Psicolinguística", de autoria de Joana Angélica da Silva de Souza, defendida em 2016, na Universidade Federal Fluminense (UFF). A partir da plasticidade cerebral e do escopo teórico da Psicolinguística sobre leitura, a autora analisa, entre outras questões, as mudanças em nosso comportamento cognitivo causadas pelo uso intenso de meios virtuais e que podem afetar, a longo prazo, nossa capacidade de decodificar e atribuir significados ao que lemos no nosso dia a dia (SOUZA, 2016).

2) "O desenvolvimento da competência leitora, da memória e das funções executivas em crianças antes e durante a alfabetização", de autoria de Marilane Maria Gregory, defendida também em 2016, na Universidade de Santa Cruz do Sul (UNISC), com base em duas grandes questões norteadoras: (a) qual é a relação entre a aprendizagem da leitura e o desenvolvimento da memória, principalmente a capacidade da memória de trabalho?; e (b) será que a aprendizagem da leitura provoca alterações nos sistemas de memória, em especial a memória de trabalho e as funções executivas? A partir de uma pesquisa experimental 
desenvolvida com 120 crianças do Rio Grande do Sul em diferentes níveis de escolaridade, a autora constatou que, mesmo sendo impossível isolar a influência da aprendizagem da leitura de fatores como maturação cognitiva (idade) e escolaridade, há uma melhora progressiva na competência leitora dos participantes e incremento na memória de trabalho no período de alfabetização (GREGORY, 2016).

3) "Sobre linguagem e interação numa instituição de longa permanência para idosos", de autoria de Katia Fernandes Bernardo, defendida em 2015, na Universidade Estadual do Sudoeste da Bahia (UESB). A partir dos pressupostos da Neurolinguística Discursiva (ND), a autora analisa a linguagem de um sujeito, morador de uma instituição de longa permanência, e estabelece relações entre a questão da regeneração das funções cerebrais, amplamente discutida na área das Neurociências, e a perspectiva sociocultural de Vygotsky (1989), que afirma que a interação com o outro é responsável pelo aprendizado e pelo desenvolvimento do indivíduo (BERNARDO, 2015).

Com efeito, a análise do estado da arte das produções acadêmicas disponíveis online no Banco de Teses e Dissertações da CAPES evidencia o interesse dos PPG, de modo geral, no estudo do cérebro, em contraste com um número pequeno de pesquisas oriundas dos PPGL. Mesmo que em menor número, o estudo das dissertações de mestrado e teses de doutorado produzidas na área de Letras/Linguística permite duas reflexões mais pontuais sobre contribuições possíveis da neurolinguística ao processo de ensino e aprendizagem de línguas. A primeira delas é referente à constatação da importância da expansão dos estudos sobre plasticidade cerebral na seara da Linguística Aplicada, para maior compreensão de fenômenos inerentes à aprendizagem de línguas (como a "fossilização de erros" e o papel da memória na aprendizagem de uma língua). A segunda, diz respeito à profícua correlação que já se esboça entre os estudos linguísticos e as perspectivas teóricas mais recentes sobre a plasticidade cerebral, sobretudo em tópicos pertinentes ao estudo da leitura (como a competência leitura e a leitura no meio digital) e da aprendizagem de línguas por idosos.

\section{Considerações finais}

Este trabalho buscou contribuir com a popularização dos debates sobre o conceito de "plasticidade cerebral" e seu impacto (in) direto em distintos campos do saber (como a Psicologia, a Educação, a 
v. 9 (3) 457-476 set-dez 2019

Linguística Aplicada, entre outros). É uma pesquisa que mais contribui para a sistematização de informações e noções importantes sobre a capacidade adaptativa do cérebro do que para qualquer outra finalidade mais ambiciosa.

Assim, primeiramente, ilustramos as noções de "plasticidade cerebral", "plasticidade neuronal", "plasticidade neural" e "plasticidade sináptica", que podem ou não ser entendidas de forma sinonímica. Optar pelo não reducionismo, contudo, parece ser a alternativa mais viável, por evidenciar as distintas maleabilidades: de modo geral, a plasticidade cerebral refere-se ao cérebro e ao SNC, a plasticidade neural, ao sistema nervoso, a plasticidade neuronal, aos neurónios, e a plasticidade sináptica, às sinapses.

Na sequência, sistematizamos algumas correlações - mais ou menos diretas - entre o conceito de plasticidade cerebral com outros, importantes para o meio acadêmico atual, como os conceitos de "inacabamento", "memória" e "fossilização de erro" nos processos de aquisição ou aprendizagem de línguas. Um olhar mais despreocupado (ou menos crítico) sobre tais conceitos pode negligenciar a ligação das perspectivas teóricas subjacentes a eles com o paradigma vigente atual dos estudos de neurolinguística, que advoga em prol de uma acepção de cérebro plástico e dinâmico.

Finalmente, sistematizamos alguns tópicos inerentes ao estado da arte da plasticidade cerebral em dissertações de mestrado e teses de doutorado oriundas de PPG no Brasil. A análise das pesquisas mapeadas indica, minimamente, o crescimento do interesse pelo tema na última década e a necessidade de mais pesquisas sobre o tema especificamente na área de Letras/Linguística.

\section{Referências bibliográficas}

AGUILAR-REBOLLEDO, F. Plasticidad cerebral: antecedentes científicos y perspectivas de desarrollo. Bol. Med. Hosp. Infant. Mex., v. 55, $\mathrm{n}^{\circ} 9$, p. 514-525, 1998. Disponível em <http://www.imbiomed.com.mx/1/1/ articulos.php? method=showDetail\&id articulo $=10593 \&$ id seccion $=361 \&$ id ejemplar=1096\&id_revista=20>. Acesso em: 17 jun. 2018.

BERNARDO, K. F. Sobre linguagem e interação numa instituição de longa permanência para idosos. 2015. 69f. Dissertação (Mestrado em Linguística) Universidade Estadual do Sudoeste da Bahia, Vitória da Conquista. 2015.

BRODAL, A. Anatomia neurológica: com correlações clínicas. 3. ed. São Paulo: Roca, 1984. 
COHEN, H. S. Neurociência para fisioterapeutas: incluindo correlações clínicas. 2. ed. São Paulo: Manole, 2001.

COLINO, A., MUÑOZ, J.; VARA, H. Plasticidad sináptica a corto plazo. Revista de Neurologia, v. 34, $n^{\circ}$ 6, p. 593-599, 2002. Disponível em: <https://www. neurologia.com/articulo/2002165>. Acesso em: 13 jun. 2018.

COSTA, A. R.; FIALHO, V. R.; BEVIlÁQUA, A. F.; LEFFA, V. J. Contribuindo com o estado da arte sobre Recursos Educacionais Abertos para o ensino e a aprendizagem de línguas no Brasil. Revista Veredas, Juiz de Fora, v. 20, p. $1-20,2016$.

DORNElES, C. L.; CARDOSO, A. A.; CARVAlHO, F. A. H. de. A educação de jovens e adultos na perspectiva das Neurociências. Revista Psicopedagogia, Associação Brasileira de Psicopedagogia. v. 29, p. 244255, 2012. Disponível em: <http://pepsic.bvsalud.org/scielo.php?script=sci arttext\&pid=S0103-84862012000200008 > . Acesso em: 10 jun. 2018.

DOUGLAS, C. R. Tratado de fisiologia: aplicada às ciências da saúde. 4. ed. São Paulo: Robe Editorial. 1999.

DURÃ̃, A. B. A. B. A fossilização de erros: o estado da questão. Signum: Estudos da Linguagem. v. 3, $\mathrm{n}^{0} 1,2000$.

EARL, L. Celebrating the Era of the Brain. The NIH Catalyst. 2014. Disponível em: <https://irp.nih.gov/catalyst/v22i6/celebrating-the-era-of-the-brain>. Acesso em: 10 jun. 2018.

FERRARI, E. A. de M.; TOYODA, M. S. S.; FALEIROS, L.; CERUTTI, S. M. Plasticidade neural: relações com o comportamento e abordagens experimentais. Psicologia: Teoria e Prática, v. 17, n. 2, p. 187-194. 2001. Disponível em: <http://www.scielo.br/scielo.php?pid=S010237722001000200011\&script=sci_abstract\&tlng=pt>. Acesso em: 19 set. 2018.

FREIRE, P. Pedagogia da autonomia: saberes necessários à prática educativa. 25. ed. São Paulo: Paz e Terra, 1996.

GARTNER, L. P.; HIATT, J. L. Tratado de histologia em cores. Rio de Janeiro: Guanabara Koogan, 1999.

GREGORY, M. M. O desenvolvimento da competência leitora, da memória e das funções executivas em crianças antes e durante a alfabetização. 2016. 163f. Dissertação (Mestrado em Letras) - Universidade de Santa Cruz do Sul, Santa Cruz do Sul. 2016.

GUTIÉRREZ, R. Plasticidad sináptica y epileptogénesis. Salud Mental, v. 21, n. 4, p. 51-54, 1998. Disponível em: <http://revistasaludmental.mx/index.php/ salud_mental/article/view/715>. Acesso em: 10 jun. 2018.

IZQUIERDO, I. Lembranças e omissões. (Entrevista). 2004a. Disponível em: <http://revistapesquisa.fapesp.br/2004/05/01/lembrancas-e-omissoes/>. Acesso em: 11 jul. 2018.

IZQUIERDO, I. Questões sobre memória. São Leopoldo: Editora Unisinos, 2004 b. 
v. 9 (3) $457-476$ set-dez 2019

JUNQUEIRA, L. C.; CARNEIRO, J. Histologia básica. 9. ed. Rio de Janeiro: Guanabara Koogan, 1999.

KUHN, T. S. A Estrutura das Revoluções Científicas. 5. ed. São Paulo: Editora Perspectiva S.A, 1997.

LAVAREDA, A.; DUARTE, J. P. A década do cérebro e da Neurotecnologia. Revista Marketing, 2016. Disponível em: <http://propmark.com.br/revistamarketing/a-decada-do-cerebro-e-da-neurotecnologia $>$. Acesso em: 18 fev. 2018.

ODA, J. Y.; SANT'ANA, D. M. G.; CARVALHO, J. Plasticidade e regeneração funcional do Sistema Nervoso: contribuição ao estudo de revisão. Arquivos de Ciências da Saúde da UNIPAR, Umuarama, v. 6, n. 2, p. 171-176, 2002.

OLIVEIRA, R. C. Corpo, pessoa, emoção - A atividade física como instrumento e reflexão de si. Revista Brasileira de Sociologia da Emoção., v. 14, no 42, p. 7587, 2015. Disponível em: <http://www.cchla.ufpb.br/rbse/RBSEv14n42dez2015. pdf\#page $=64>$. Acesso em: 12 jul. 2018.

PINTO, A. L. F. Memória: um desafio à autonomia do idoso. Família, Saúde e Desenvolvimento, Curitiba, v. 1, n. 1/2, p. 39-48, jan./dez. 1999.

REGO, T. C. Vygotsky: uma perspectiva histórico-cultural da educação. Petrópolis: Vozes. 1995.

ROSENZWEIG, M. R. Aspects of the search for neural mechanisms of memory. Annual Review of Psychology., v. 47, p. 1-32, 1996. Disponível em: <https:// www.ncbi.nlm.nih.gov/pubmed/8624134>. Acesso em: 28 jul. 2018.

SILVA, M. F. M. C.; KLEINHANS, A. C. S. Processos cognitivos e plasticidade cerebral na Síndrome de Down. Revista Brasileira de Educação Especial, v. $12, \mathrm{n}^{0} 1,2006$.

SOUZA, J. A. S. A leitura dos nativos digitais: uma abordagem Psicolinguística. 2016. 117f. Dissertação (Mestrado em Estudos de Linguagem) - Universidade Federal Fluminense, Niterói. 2016.

VENTURA, D. F. Um retrato da Área de Neurociência e Comportamento no Brasil. Revista Psicologia: Teoria e Pesquisa, v. 26, no Especial, p. 123-129, 2010. Disponível em: <http://www.scielo.br/pdf/ptp/v26nspe/a11v26ns.pdf>. Acesso em: 28 jan. 2018.

VYGOTSKY, L. S. Pensamento e linguagem. São Paulo: Martins Fontes, 1989. 